\title{
Long-term exposure to ambient ultrafine particles and respiratory disease incidence in in Toronto, Canada: a cohort study
}

Scott Weichenthal ${ }^{1,2^{*}}$, Li Bai ${ }^{3,4}$, Marianne Hatzopoulou ${ }^{5}$, Keith Van Ryswyk ${ }^{2}$, Jeffrey C. Kwong ${ }^{3,4,6}$, Michael Jerrett ${ }^{7}$, Aaron van Donkelaar ${ }^{8}$, Randall V. Martin ${ }^{8,9}$, Richard T. Burnett ${ }^{10}$, Hong Lu ${ }^{4}$ and Hong Chen ${ }^{3,4,11}$

\begin{abstract}
Background: Little is known about the long-term health effects of ambient ultrafine particles $(<0.1 \mu \mathrm{m})$ (UFPs) including their association with respiratory disease incidence. In this study, we examined the relationship between long-term exposure to ambient UFPs and the incidence of lung cancer, adult-onset asthma, and chronic obstructive pulmonary disease (COPD).

Methods: Our study cohort included approximately 1.1 million adults who resided in Toronto, Canada and who were followed for disease incidence between 1996 and 2012. UFP exposures were assigned to residential locations using a land use regression model. Random-effect Cox proportional hazard models were used to estimate hazard ratios (HRs) describing the association between ambient UFPs and respiratory disease incidence adjusting for ambient fine particulate air pollution $\left(\mathrm{PM}_{2.5}\right), \mathrm{NO}_{2}$, and other individual/neighbourhood-level covariates.

Results: In total, 74,543 incident cases of COPD, 87,141 cases of asthma, and 12,908 cases of lung cancer were observed during follow-up period. In single pollutant models, each interquartile increase in ambient UFPs was associated with incident COPD ( $\mathrm{HR}=1.06,95 \% \mathrm{Cl}: 1.05,1.09)$ but not asthma ( $\mathrm{HR}=1.00,95 \% \mathrm{Cl}: 1.00,1.01)$ or lung cancer ( $\mathrm{HR}=1.00,95 \% \mathrm{Cl}: 0.97,1.03)$. Additional adjustment for $\mathrm{NO}_{2}$ attenuated the association between UFPs and COPD and the HR was no longer elevated ( $\mathrm{HR}=1.01,95 \% \mathrm{Cl}: 0.98,1.03) . \mathrm{PM}_{2.5}$ and $\mathrm{NO}_{2}$ were each associated with increased incidence of all three outcomes but risk estimates for lung cancer were sensitive to indirect adjustment for smoking and body mass index.

Conclusions: In general, we did not observe clear evidence of positive associations between long-term exposure to ambient UFPs and respiratory disease incidence independent of other air pollutants. Further replication is required as few studies have evaluated these relationships.
\end{abstract}

Keywords: Ultrafine particles, Cohort study, Asthma, Copd, Lung cancer

\section{Background}

Short-term exposures to ambient ultrafine particles (UFPs) $(<0.1 \mu \mathrm{m})$ have been associated with acute changes in physiological measures of cardiorespiratory health $[1,2]$ but little is known about the long-term health effects of these pollutants. Recently, Ostro et al. [3] applied a chemical transport model to estimate UFP exposures (on a

\footnotetext{
*Correspondence: scott.weichenthal@mcgill.ca

'Department of Epidemiology, Biostatistics, and Occupational Health and Gerald Bronfman Department of Oncology, McGill University, 1020 Pine Avenue, West, Montreal, QC H3A 1A2, Canada

${ }^{2}$ Air Health Science Division, Health Canada, Ottawa, Canada

Full list of author information is available at the end of the article
}

$3 \times 3 \mathrm{~km}$ scale) for women in the California Teachers Study cohort and reported a positive association between ambient UFPs and ischemic heart disease mortality. Moreover, various sources/components of ambient UFPs were independently associated with ischemic heart disease mortality including elemental/organic carbon, metals (copper and iron), and emissions from gasoline and diesel engines [3]. Ambient UFPs were not associated with all-cause mortality or respiratory mortality (including lung cancer). To our knowledge, this is the only cohort study to date to evaluate the long-term health effects of ambient UFPs and 
studies have yet to evaluate the relationship between UFPs and the incidence of respiratory diseases.

In this study, we examined the association between long-term exposure to ambient UFPs and the incidence of lung cancer, adult-onset asthma, and chronic obstructive pulmonary disease (COPD) in Toronto, Canada. Longterm ambient UFP exposures were assigned to the residential locations of cohort members using a land use regression model developed for Toronto [4]. Our primary aim in conducting this study was to determine if ambient UFPs are independently associated with respiratory disease incidence after adjusting for other air pollutants including fine particulate air pollution $\left(\mathrm{PM}_{2.5}\right)$ and nitrogen dioxide $\left(\mathrm{NO}_{2}\right)$.

\section{Methods}

\section{Study population}

Our study was conducted using the Ontario Population Health and Environment Cohort (ONPHEC), a large population-based cohort in Ontario Canada. Details of the ONPHEC cohort are provided elsewhere [5]. Briefly, this cohort is comprised of all adults in Ontario who, on April 1, 1996 and onwards, were registered with Ontario's provincial health insurance plan, resided in Ontario for $\geq 5$ years, and were Canadian-born. The cohort was created through record linkages of population-based health administrative databases developed from the Ontario universal healthcare system.

Our analysis included all cohort members who, on April 1,1996 , resided in the city of Toronto, were aged between 30 and 100 years, and were free of the conditions under investigation. Cohort members were followed until December 31, 2012 to determine incident cases of asthma and chronic obstructive pulmonary disease (COPD). For lung cancer, follow-up began on April 1, 2001 to allow for a minimum 5-year time lag in exposure.

\section{Outcomes}

All health data (including comorbidity data for diabetes, congestive heart failure (CHF), hypertension, acute myocardial infarction (AMI) and all cancers) were obtained from databases housed at the Institute for Clinical and Evaluative Sciences (ICES). This study used the following databases: 1) Registered Persons Database (for age, sex, residential history and health insurance eligibility); 2) Ontario COPD Database (for incident COPD); 3) Ontario Asthma Surveillance Information System (for incident asthma); 4) Ontario Cancer Registry (for incident lung cancer); 5) Census at the dissemination area level (for income quintile, census tract-level unemployment rate, education and mean household income); and 6) National Population Health Survey and Canadian Community Health Survey (for smoking habits and BMI used in the indirect adjustment). The International Classification of
Diseases, Ninth Revision (ICD-9) codes for COPD and asthma and the third edition of the International Classification of Diseases for Oncology (ICD-O-3) codes for lung cancer are presented in Table 1.

\section{Air pollution exposure}

Estimates of long-term average exposure to ambient UFP and $\mathrm{NO}_{2}$ were derived from land use regression models developed for the city of Toronto $[4,6]$. UFP exposure estimates were based on measurements collected in 2014 [4, 7] while $\mathrm{NO}_{2}$ exposure estimates were based on measurements collected in 2004 [6]. Briefly, the UFP model was based on data collected from a mobile monitoring campaign conducted over three weeks ( 2 weeks in summer, 1 week in winter) including data from 405 road segments distributed across the city of Toronto. Recent evidence from Amsterdam suggests that short-term monitoring campaigns can be used to develop models to predict past spatial variations in ambient UFPs [8]. The UFP model used in this study included parameters for the natural logarithm of the distance to highways, major roads, the central business district, Pearson international airport, and bus routes as well as land use variables for park land (100-m buffer), open space (100-m buffer), on-street trees (100-m buffer), and length of bus routes (100-m buffer). The model $R^{2}$ value was 0.67 ; when evaluated on an external sample of 151 data points the $R^{2}$ value was 0.50 and the mean difference between measured and predicted values was -1385 particles $/ \mathrm{cm}^{3}$ (95\% CI: -3754, 982) [4].

The $\mathrm{NO}_{2}$ model was based on data collected from 94 sites across Toronto and included variables for the lengths of expressways (200-m buffer) and major roads (50-m buffer), industrial land use (750-m buffer), density of dwellings (2000-m buffer), 24-h traffic counts (500-m buffer), and being downwind of an expressway within $1500 \mathrm{~m}$. The model $R^{2}$ value for the $\mathrm{NO}_{2}$ model was

Table 1 Diagnostic codes for selected outcomes and comorbidities in this study

ICD-9/ICD-O-3 codes

\begin{tabular}{ll}
\hline $\begin{array}{l}\text { Selected outcomes } \\
\text { Chronic obstructive pulmonary } \\
\text { disease (COPD) }\end{array}$ & $491,492,496$ \\
Asthma & 493 \\
Lung cancer & C34.0 - C34.9 a \\
Comorbid health conditions & \\
Diabetes & 250 \\
Hypertension & $401-405$ \\
Congestive Heart Failure (CHF) & 428 \\
Acute myocardial infarction (AMI) & 410 \\
All cancer & $140-208$
\end{tabular}

${ }^{\mathrm{a}}$ Malignant lung tumors (behaviour code 3 ) 
0.69 and bias was estimated to be less than $4 \%$ in crossvalidation procedures (a cross-validation $R^{2}$ was not reported) [6]. Estimates of long-term average $\mathrm{PM}_{2.5}$ concentrations (1998-2011) were derived from satellite observations at a spatial resolution of approximately $1 \mathrm{~km} \times 1 \mathrm{~km}$ as previously described [9]. These estimates have been shown to agree closely with ground-level monitoring data across North America $\left(R^{2}=0.82\right)$ [9].

Three-year moving average exposures (based on place of residence) were used for the main analyses.

\section{Covariates}

Individual level covariate data are limited in the ONPHEC cohort. We compiled the following covariates at baseline: age, sex and five comorbidities including diabetes, CHF, hypertension, AMI and all cancers (ICD-9 codes in Table 1). We further created four neighbourhood-level variables using 1996, 2001, and 2006 Canadian Census Dissemination data: 1$)$ the proportion of recent immigrants; 2) the proportion of population aged $\geq 15$ years who had not completed high school; 3) unemployment rate; and 4) mean household income.

\section{Statistical methods}

We estimated hazard ratios (HRs) using Cox proportional hazards models stratified by sex and one-year age groups. Continuous measures of long-term exposures to UFPs, $\mathrm{PM}_{2.5}$ and $\mathrm{NO}_{2}$ were included in the models as time-dependent variables using a 3-year moving average. For the incidence of lung cancer, a 5-year time lag in the exposure was used (i.e. the most recent 5 -years were excluded from the moving average exposure). Follow-up ended if participants died, became ineligible for provincial health insurance (i.e. movement out of province), moved outside of Toronto, or at the end of follow-up (December 31, 2012).

For all three outcomes, we incrementally adjusted for a series of covariates including comorbidities and neighbourhood-level contextual variables. We also evaluated the impact of including a frailty term for neighbourhood ( $n=140$ in the city of Toronto) to account for any unmeasured confounding factors at the neighbourhood level that may be associated with both exposure and outcomes. Finally, we examined multi-pollutant models including UFPs, $\mathrm{NO}_{2}$ and $\mathrm{PM}_{2.5}$ and investigated potential effect modification by age and sex. In addition, we conducted stratified analyses to evaluate potential effect modification by $\mathrm{NO}_{2}$ in associations between particulate air pollutants and respiratory outcomes. All HRs and $95 \%$ confidence intervals (CIs) reflect interquartile range (IQR) increases in air pollution concentrations.

A series of sensitivity analyses were conducted to test the robustness of our results. Specifically, UFP concentrations (our primary exposure of interested) were additionally modelled across quintiles of exposure. In addition, we considered mean annual exposures for each pollutant over other time windows including one and two year moving averages; we restricted analyses to participants who had lived at their baseline address for more than 5 years prior to cohort entry; we adjusted for a linear term for time to account for potential changes in the risk of outcomes of interest over time; we adjusted for distance to major roadways; and we indirectly adjusted for potential confounding by smoking and BMI [10]. For lung cancer, we also tested the sensitivity of the results by repeating the analyses after taking into account 0-year (no time lag) and 2-year lags in the exposure estimates. Finally, models for asthma and COPD were additional adjusted for prevalent lung cancer as a surrogate measure of smoking.

Indirect adjustment analyses (to estimate the association between air pollution exposures and adjustment variables for smoking and BMI) made use of data on 3807 subjects in the city of Toronto from the Canadian Community Health Survey from the 2001, 2003, 2005 and 2007 panels who were between 30 and 100 years of age [10]. The hazard ratios between adjustment variables and respiratory disease incidence were directly calculated from the CCHS data because recent systematic reviews of the associations between our selected incidence outcomes and missing risk factors (i.e. smoking and BMI) were not identified. However, we did compare hazard ratios calculated using the CCHS respondents with those reported in previous studies, and found similar results. Specifically, lung cancer incidence was substantially higher in current $(\mathrm{HR}=13.67,95 \% \mathrm{CI}: 3.46-54.03)$ and former smokers $(\mathrm{HR}=4.18,95 \% \mathrm{CI} 1.15-15.23)$ in the CCHS respondents compared to never smokers. Similarly, the Women's Health Initiative Observational Study (WHI-OS) in the US reported that HRs for lung cancer incidence were 13.44 (95\% CI: $10.80-16.75)$ and 4.20 (95\% CI: 3.48-5.08) in current and formers smokers, respectively, relative to never smokers [11]. The population characteristics of the CCHS cohort used for indirect adjustment were also similar to our study populations (i.e. $45 \%$ male, mean age of 58 years, and hypertension prevalence of $18.2 \%$ ).

Details of the indirect adjustment procedure have been describe previously [12]. Briefly, motivated by the theory of partitioned regression for linear regression models, this method allows for adjusting the HRs for these risk factors unavailable in the dataset, while simultaneously controlling for all risk factors included in the Cox models (e.g., comorbidities and neighborhood-level covariates). The method requires estimates of the spatial associations between the variables included in the Cox models and the unobserved variables. These estimated relationships were then used to indirectly adjust for smoking (never, former, or current cigarette smoker) and 
BMI $\left(<25.0,25.0-29.9\right.$, or $\left.\geq 30 \mathrm{~kg} / \mathrm{m}^{2}\right)$ for the entire cohort (see Additional file 1: Table S1). The Delta values reported in Table S1 refer to estimated associations between the omitted variables (i.e. smoking and BMI) and the concentrations of UFPs, $\mathrm{PM}_{2.5}$, and $\mathrm{NO}_{2}$. Negative values indicate inverse relationships between the prevalence of the omitted variables and levels of pollution.

\section{Results}

In total, 74,543 incident cases of COPD (mean follow-up 14.4 years), 87,141 cases of adult-onset asthma (mean follow-up 14.0 years), and 12,908 cases of lung cancer (mean follow-up 14.6 years) were identified over the follow-up period (Table 2). Men and women were present in our cohort in approximately equal proportions and participants had a mean age of approximately 50 years at baseline (Table 2). Approximately 22\% of each baseline cohort population moved outside the city of Toronto during the follow-up period. UFP exposures varied substantially across Toronto ranging from less than $10,000 / \mathrm{cm}^{3}$ to more than $100,000 / \mathrm{cm}^{3}$ (Table 3). Spatial variations in ambient $\mathrm{PM}_{2.5}$ and $\mathrm{NO}_{2}$ concentrations were less dramatic but still covered the range of exposures typically observed across Canada (Table 3). Estimated UFP exposures were weakly correlated with $\mathrm{PM}_{2.5}(r=-0.26)$ and $\mathrm{NO}_{2}(r=0.23) ; \mathrm{PM}_{2.5}$ and $\mathrm{NO}_{2}$ were also weakly correlated $(r=0.22)$. These correlations are consistent with those previously observed in a panel study of personal air pollution exposures in Canada [13]. A scatter plot of NO2 and UFP concentrations is provided in Additional file 1: Figure S1.

Hazard ratios describing the associations between ambient air pollutants and respiratory disease incidence are shown in Table 4. UFP exposures were not associated with increased lung cancer incidence. Small positive associations were observed between UFPs and asthma and COPD in single pollutant models but the magnitudes of these associations decreased when other air pollutants were included in the models (Fig. 1). The relationship between UFPs and COPD was also sensitive (and change directions) to the inclusion of a frailty term for neighbourhood suggesting an important impact of unmeasured confounding factors. When UFP exposures were modelled categorically across quintiles, COPD and asthma incidence were each increased in the four upper quintiles compared to the lowest category of

Table 2 Baseline characteristics of study subjects and their neighborhoods

\begin{tabular}{|c|c|c|c|c|c|c|}
\hline \multirow[t]{2}{*}{ Characteristics of the cohort } & \multicolumn{2}{|l|}{ COPD } & \multirow{2}{*}{$\begin{array}{l}\text { Asthma } \\
\text { Total cohort } \\
\text { population }\end{array}$} & \multirow[b]{2}{*}{$\begin{array}{l}\text { Incident } \\
\text { cases }\end{array}$} & \multicolumn{2}{|l|}{ Lung cancer $^{a}$} \\
\hline & $\begin{array}{l}\text { Total cohort } \\
\text { population }\end{array}$ & $\begin{array}{l}\text { Incident } \\
\text { cases }\end{array}$ & & & $\begin{array}{l}\text { Total cohort } \\
\text { population }\end{array}$ & $\begin{array}{l}\text { Incident } \\
\text { cases }\end{array}$ \\
\hline Number & $1,105,258$ & 74,543 & $1,057,722$ & 87,141 & $1,039,128$ & 12,908 \\
\hline$\%$ & - & 6.7 & - & 8.2 & - & 1.2 \\
\hline \multicolumn{7}{|l|}{ Individual risk factors at time of entry } \\
\hline Age, years (SD) & $51.4(15.3)$ & $62.2(13.5)$ & $51.8(15.4)$ & $51.8(14.7)$ & $50.7(14.6)$ & $60.0(11.0)$ \\
\hline Men (\%) & 47 & 52.5 & 47.8 & 40.2 & 46.9 & 54.9 \\
\hline \multicolumn{7}{|l|}{ Pre-existing comorbidity (\%) } \\
\hline Diabetes & 6.8 & 11.4 & 6.8 & 7.3 & 6.3 & 8.0 \\
\hline Chronic obstructive pulmonary disease (COPD) & - & - & 1.7 & 4.2 & 2.0 & 8.0 \\
\hline Asthma & 6 & 15.2 & - & - & 6.7 & 8.5 \\
\hline Acute myocardial infarction (AMI) & 0.7 & 1.5 & 0.7 & 0.7 & 0.6 & 1.2 \\
\hline Hypertension & 20.8 & 33.8 & 20.8 & 23.4 & 19.9 & 26.8 \\
\hline Congestive Heart Failure (CHF) & 1.7 & 4.4 & 1.9 & 1.9 & 1.2 & 1.9 \\
\hline Cancer & 3.7 & 6.6 & 3.8 & 3.5 & 3.0 & - \\
\hline \multicolumn{7}{|l|}{$\begin{array}{l}\text { Area level risk factors from Canadian Census at the } \\
\text { census tract level at baseline }\end{array}$} \\
\hline $\begin{array}{l}\text { Percentage of the population } 15 \text { years of age } \\
\text { and older with less than a high school education }\end{array}$ & 32 & 34.2 & 31.9 & 33.3 & 32.0 & 33.8 \\
\hline $\begin{array}{l}\text { Percentage of the population } 15 \text { years of age and } \\
\text { older without employment }\end{array}$ & 10.3 & 10.9 & 10.3 & 10.9 & 10.3 & 10.8 \\
\hline Percentage of recent immigrants & 11.1 & 10.6 & 11 & 11.5 & 11.1 & 10.8 \\
\hline $\begin{array}{l}\text { Average household income with all ages } \\
\text { (in } \$ 1000 \text { CAN) (SD) }\end{array}$ & $62.1(37.4)$ & $57.9(34.8)$ & $62.2(37.6)$ & $58.9(35.2)$ & $62.0(37.3)$ & $57.8(33.6)$ \\
\hline
\end{tabular}

SD standard deviation

aLung cancer cohort was followed from April 1, 2001 to December 31, 2012 
Table 3 Descriptive statistics for estimated long-term average air pollution concentrations at baseline

\begin{tabular}{llllllllll}
\hline Pollutant & IQR & Mean (SD) & Min & 5th & 25th & 50th & 75th & 95 th & Max \\
\hline UFPs $\left(\right.$ count $\left./ \mathrm{cm}^{3}\right)$ & 10,097 & $28,473(9226)$ & 6772 & 18,184 & 22,186 & 26,000 & 32,320 & 58,862 & 109,759 \\
$\mathrm{PM}_{2.5}\left(\mathrm{\mu g} / \mathrm{m}^{3}\right)$ & 3.2 & $10.9(2.1)$ & 3.9 & 7.2 & 9.9 & 10.7 & 13.1 & 13.8 & 14.9 \\
$\mathrm{NO}_{2}(\mathrm{ppb})$ & 4.1 & $21.4(3.5)$ & 9.9 & 16.4 & 19.1 & 21.1 & 23.2 & 32.8 & 48.9 \\
\hline
\end{tabular}

SD standard deviation, IQR interquartile range

exposure; these risk estimates decreased (but remained elevated) when $\mathrm{PM}_{2.5}$ and $\mathrm{NO}_{2}$ were included in the models(Table 5).

Ambient $\mathrm{PM}_{2.5}$ and $\mathrm{NO}_{2}$ were each associated with modest increases (i.e. 1-12\% in fully adjusted models) in the incidence of all three respiratory outcomes and associations were robust to adjustment for medial comorbidities, neighbourhood level covariates, and other air pollutants. However, including a frailty term in models for $\mathrm{PM}_{2.5}$ (COPD and lung cancer models) and $\mathrm{NO}_{2}$ (COPD model) also impacted risk estimates with hazard ratios increasing for $\mathrm{NO}_{2}$ and decreasing for $\mathrm{PM}_{2.5}$.

For UFPs and $\mathrm{NO}_{2}$, associations with incident COPD were strongest among younger subjects; however, other observed associations did not differ substantially by age or sex (Table 6). There was no clear evidence of effect modification by $\mathrm{NO}_{2}$ in stratified analyses of associations between particulate air pollutants and respiratory outcomes (Additional file 1: Table S2). Additional adjustment of asthma and COD models for prevalent lung cancer did not materially change results for any of the pollutants (data not shown).

Sensitivity analyses for $\mathrm{PM}_{2.5}$ and $\mathrm{NO}_{2}$ are shown in Tables 7 and 8. The hazard ratios for $\mathrm{PM}_{2.5}, \mathrm{NO}_{2}$, and lung cancer were sensitive to indirect adjustment for smoking and BMI and the magnitudes of these associations decreased when these parameters were included in the model. The magnitudes of associations between $\mathrm{PM}_{2.5}$ and $\mathrm{NO}_{2}$ and $\mathrm{COPD} /$ asthma were robust (i.e. changes of $1-2 \%$ ) to various modeling approaches including indirect adjustment for smoking and obesity (Tables 7-8). Hazard ratios for UFPs and lung cancer

Table 4 Hazard ratios (HR) and 95\% Cls for the incidence of chronic obstructive pulmonary disease (COPD), adult-onset asthma and lung cancer in relation to an IQR increases in each pollutant in Toronto, Canada

\begin{tabular}{|c|c|c|c|c|c|c|c|c|c|c|}
\hline \multirow{3}{*}{$\begin{array}{l}\text { Exposure } \\
\text { UFPS }\end{array}$} & \multirow{3}{*}{$\begin{array}{l}\text { Model } \\
\text { UFPs only }^{\mathrm{b}}\end{array}$} & \multicolumn{3}{|c|}{ COPD (1996-2012) } & \multicolumn{3}{|c|}{ Asthma (1996-2012) } & \multicolumn{3}{|c|}{ Lung cancer ${ }^{\mathrm{a}}$ (2001-2012) } \\
\hline & & \multirow{2}{*}{$\begin{array}{l}\mathrm{HR} \\
0.96\end{array}$} & \multicolumn{2}{|c|}{$95 \% \mathrm{Cl}$} & \multirow{2}{*}{$\begin{array}{l}\mathrm{HR} \\
1.02\end{array}$} & \multicolumn{2}{|c|}{$95 \% \mathrm{Cl}$} & \multirow{2}{*}{$\begin{array}{l}\mathrm{HR} \\
0.97\end{array}$} & \multicolumn{2}{|c|}{$95 \% \mathrm{Cl}$} \\
\hline & & & 0.95 & 0.97 & & 1.01 & 1.02 & & 0.95 & 0.99 \\
\hline & + Neighborhood-level covariates ${ }^{c}$ & 0.95 & 0.94 & 0.96 & 1.00 & 0.99 & 1.01 & 0.97 & 0.95 & 0.99 \\
\hline & + frailty term for neighborhoods & 1.06 & 1.04 & 1.08 & 1.01 & 1.00 & 1.02 & 1.00 & 0.97 & 1.03 \\
\hline & + Medical comorbidities $^{d}$ & 1.06 & 1.04 & 1.08 & 1.00 & 1.00 & 1.01 & 1.00 & 0.97 & 1.04 \\
\hline & $+\mathrm{PM}_{2.5} \mathrm{e}^{\mathrm{e}}$ & 1.07 & 1.05 & 1.09 & 1.01 & 1.00 & 1.02 & 1.00 & 0.97 & 1.04 \\
\hline & $+\mathrm{NO}_{2}{ }^{\mathrm{e}}$ & 1.01 & 0.98 & 1.03 & 1.00 & 0.99 & 1.01 & 0.98 & 0.94 & 1.01 \\
\hline & $+\mathrm{PM}_{2.5}$ and $\mathrm{NO}_{2}{ }^{\mathrm{e}}$ & 1.01 & 0.98 & 1.03 & 1.00 & 0.99 & 1.01 & 0.98 & 0.95 & 1.01 \\
\hline \multirow[t]{5}{*}{$\mathrm{PM}_{2.5}$} & $\mathrm{PM}_{2.5}$ only & 1.07 & 1.06 & 1.09 & 1.01 & 1.00 & 1.02 & 1.09 & 1.06 & 1.12 \\
\hline & + Neighborhood-level covariates ${ }^{d}$ & 1.10 & 1.08 & 1.11 & 1.02 & 1.01 & 1.04 & 1.11 & 1.07 & 1.14 \\
\hline & + frailty term for neighborhoods & 1.06 & 1.04 & 1.08 & 1.02 & 1.00 & 1.04 & 1.05 & 1.03 & 1.08 \\
\hline & + Medical comorbidities & 1.06 & 1.04 & 1.08 & 1.02 & 1.00 & 1.04 & 1.05 & 1.03 & 1.08 \\
\hline & $+\mathrm{NO}_{2} \mathrm{e}^{\mathrm{s}}$ & 1.04 & 1.02 & 1.07 & 1.01 & 1.00 & 1.03 & 1.04 & 1.02 & 1.07 \\
\hline \multirow[t]{5}{*}{$\mathrm{NO}_{2}$} & $\mathrm{NO}_{2}$ only & 1.10 & 1.09 & 1.11 & 1.04 & 1.03 & 1.05 & 1.09 & 1.06 & 1.11 \\
\hline & + Neighborhood-level covariates ${ }^{d}$ & 1.06 & 1.05 & 1.07 & 1.03 & 1.02 & 1.03 & 1.06 & 1.04 & 1.08 \\
\hline & + frailty term for neighborhoods & 1.11 & 1.07 & 1.15 & 1.03 & 1.02 & 1.05 & 1.07 & 1.04 & 1.10 \\
\hline & + Medical comorbidities & 1.11 & 1.07 & 1.15 & 1.03 & 1.02 & 1.05 & 1.07 & 1.04 & 1.10 \\
\hline & $+\mathrm{PM}_{2.5} \mathrm{e}^{\mathrm{a}}$ & 1.12 & 1.08 & 1.15 & 1.03 & 1.02 & 1.05 & 1.08 & 1.05 & 1.11 \\
\hline
\end{tabular}

${ }^{a}$ Cohort for lung cancer was followed up from April 1, 2001 to December 31, 2012 and a 5-year lag in exposure was used

${ }^{b}$ Stratified by one-year age and sex

cNeighborhood-level covariates include percentage of the population 15 years of age and older with less than a high school education, percentage of the population 15 years of age and older without employment, percentage of recent immigrants, and average household income

${ }^{\mathrm{d}}$ For COPD and asthma, we included comorbid diabetes, CHF, AMI, hypertension and all cancer; For lung cancer, we included comorbid diabetes, CHF, AMI and hypertension

${ }^{\mathrm{e}}$ Fully adjusted models 


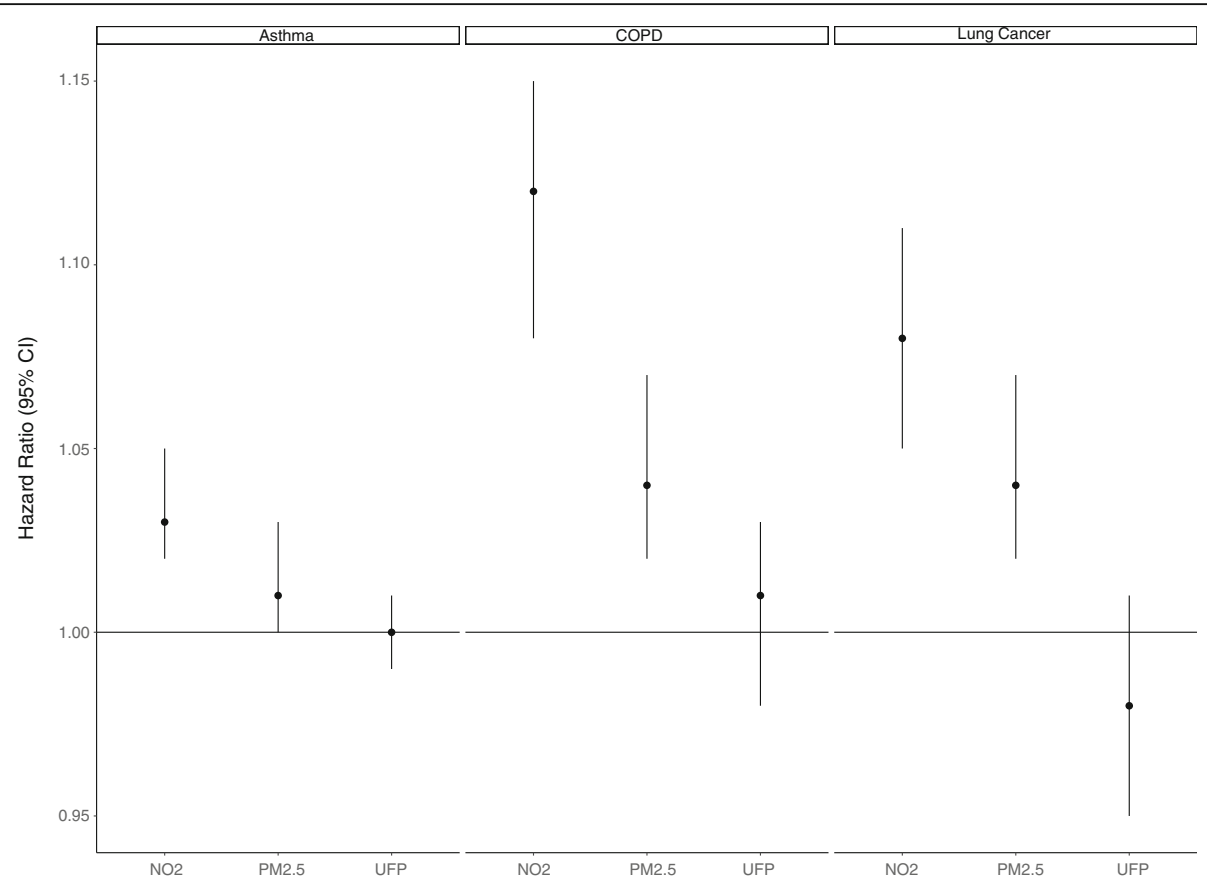

Fig. 1 Hazard ratios (HR) and 95\% Cls for the incidence of chronic obstructive pulmonary disease (COPD), adult-onset asthma and lung cancer in relation to an IQR increases in each pollutant in Toronto, Canada. All models are stratified by one-year age and sex and are adjusted for neighborhoodlevel covariates including percentage of the population 15 years of age and older with less than a high school education, percentage of the population 15 years of age and older without employment, percentage of recent immigrants, and average household income. For COPD and asthma, comorbid diabetes, CHF, AMl, hypertension, and all cancers were included as covariates. For lung cancer, we included comorbid diabetes, CHF, AMI and hypertension. Models for UFPs are adjusted for $\mathrm{NO}_{2}$ and $\mathrm{PM}_{2.5}$. Models for $\mathrm{NO}_{2}$ are adjusted for $\mathrm{PM} \mathrm{M}_{2.5}$; $\mathrm{PM}_{2.5}$ models are adjusted for $\mathrm{NO}_{2}$

and asthma remained null in all sensitivity analyses while positive associations were generally observed between UFPs and COPD (Additional file 1: Table S3).

\section{Discussion}

A number of studies have observed short-term cardiovascular and respiratory health effects of ambient UFPs $[1,2]$ but little is known about the long-term health effects of these pollutants. We conducted a large population-based study to examine the relationship between long-term exposure to ambient UFPs and respiratory disease incidence in Toronto, Canada. In general, we did not observe clear evidence of positive associations between UFPs and respiratory disease incidence independent of other air pollutants although positive associations were observed between UFPs and incident COPD.

To our knowledge, only one previous cohort study has evaluated the long-term health effects of ambient UFPs. Specifically, Ostro et al. [3] reported positive associations between UFP concentrations (and various components) and ischemic heart disease mortality but UFPs were not associated with mortality from respiratory outcomes. Our findings are consistent with this result as we did not observe clear evidence of associations between ambient
UFPs and any of the respiratory outcomes examined. On the other hand, spatial variations in long-term average ambient $\mathrm{NO}_{2}$ and $\mathrm{PM}_{2.5}$ concentrations were positively associated with lung cancer incidence and this is consistent with existing evidence related to outdoor air pollution and lung cancer risk $[14,15]$; however, these associations were sensitive to indirect adjustment for smoking and BMI in our analyses.

In general, it is not clear why UFPs would not be associated with lung cancer incidence as diesel exhaust is a known carcinogen [16] and diesel vehicles are an important source of UFPs in urban areas [7, 17]. One explanation may be that the rapid condensation/ agglomeration of UFPs into larger particles tends to concentrate carcinogenic substances into larger particle size fractions and this hypothesis is supported by previous associations between $\mathrm{PM}_{2.5}$ and lung cancer [14]. Alternatively, residential estimates of long-term average UFP concentrations may not adequately capture long-term personal exposures as other micro-environments (such as transportation) [7] likely also contribute substantially to UFP exposures. In the future, it may be interesting to incorporate mobility information (e.g. both home and workplace location) into exposure assessment in large population-based studies to see if this has an important 
Table 5 Hazard ratios (HR) and 95\% Cls for the incidence of chronic obstructive pulmonary disease (COPD), adult-onset asthma, and lung cancer across quintiles of ambient UFP concentrations in Toronto, Canada

\begin{tabular}{|c|c|c|c|c|c|c|c|c|c|}
\hline \multirow[t]{2}{*}{ Exposure } & \multicolumn{3}{|c|}{ COPD } & \multicolumn{3}{|c|}{ Asthma } & \multicolumn{3}{|c|}{ Lung cancer } \\
\hline & $\mathrm{HR}$ & \multicolumn{2}{|l|}{$95 \% \mathrm{Cl}$} & $\mathrm{HR}$ & \multicolumn{2}{|l|}{$95 \% \mathrm{Cl}$} & $\mathrm{HR}$ & \multicolumn{2}{|l|}{$95 \% \mathrm{Cl}$} \\
\hline \multicolumn{10}{|c|}{ Single Pollutant Model } \\
\hline \multicolumn{10}{|c|}{ UFPs (by quintiles) ${ }^{a}$} \\
\hline Q1 & 1.00 & & & 1.00 & & & 1.00 & & \\
\hline Q2 & 1.05 & 1.03 & 1.09 & 1.04 & 1.01 & 1.06 & 0.97 & 0.90 & 1.03 \\
\hline Q3 & 1.12 & 1.08 & 1.15 & 1.05 & 1.02 & 1.08 & 1.00 & 0.92 & 1.07 \\
\hline Q4 & 1.16 & 1.13 & 1.19 & 1.06 & 1.03 & 1.09 & 1.03 & 0.95 & 1.10 \\
\hline Q5 & 1.12 & 1.08 & 1.17 & 1.06 & 1.03 & 1.10 & 0.96 & 0.87 & 1.05 \\
\hline \multicolumn{10}{|c|}{ Adjusted for $\mathrm{NO}_{2}$ and $P M_{2.5}$} \\
\hline \multicolumn{10}{|l|}{ UFPs $^{a}$} \\
\hline Q1 & 1.00 & & & 1.00 & & & 1.00 & & \\
\hline Q2 & 1.04 & 1.02 & 1.07 & 1.03 & 1.01 & 1.06 & 0.95 & 0.89 & 1.02 \\
\hline Q3 & 1.08 & 1.05 & 1.11 & 1.04 & 1.01 & 1.06 & 0.97 & 0.90 & 1.04 \\
\hline Q4 & 1.10 & 1.06 & 1.13 & 1.04 & 1.01 & 1.07 & 0.99 & 0.92 & 1.07 \\
\hline Q5 & 1.03 & 0.98 & 1.08 & 1.03 & 0.99 & 1.07 & 0.91 & 0.82 & 1.00 \\
\hline
\end{tabular}

${ }^{a}$ Hazard ratios by quintiles of distributions were estimated in the single-pollutant models stratified by age and sex and adjusted for medical comorbidities and neighborhood-level variables. For COPD, quintiles of UFPs: Q1, $\leq 21,473 ; \mathrm{Q} 2,21,473-24,349 ; \mathrm{Q} 3,24,349-27,813 ; \mathrm{Q} 4,27,813-34,763 ; \mathrm{Q} 5,>34,763$ count/cm ${ }^{3}$. For asthma, quintiles of UFPs: Q1, $\leq 21,459 ;$ Q2, 21,459-24,325; Q3, 24,325-27,788; Q4, 27,788-34,726; Q5, > 34,726 count/cm³. For lung cancer, quintiles of UFPs: Q1, $\leq 21,464 ; \mathrm{Q} 2,21,464-24,329 ; \mathrm{Q} 3,24,329-27,793 ; \mathrm{Q} 4,27,793-34,758 ; \mathrm{Q} 5,>34,758 \mathrm{count} / \mathrm{cm}^{3}$

Table 6 Hazard ratios and 95\% Cl for the associations of incident COPD, adult-onset asthma, and lung cancer with an IQR increase in each pollutant by age and sex in Toronto, Canada

\begin{tabular}{|c|c|c|c|c|c|c|c|c|c|c|c|}
\hline \multirow[t]{2}{*}{ Covariates } & \multirow[t]{2}{*}{ No. of cases } & & \multicolumn{3}{|l|}{ UFPs } & \multicolumn{3}{|l|}{$\mathrm{PM}_{2.5}$} & \multicolumn{3}{|l|}{$\mathrm{NO}_{2}$} \\
\hline & & & $\mathrm{HR}$ & \multicolumn{2}{|l|}{$95 \% \mathrm{Cl}$} & $\mathrm{HR}$ & \multicolumn{2}{|l|}{$95 \% \mathrm{Cl}$} & $\mathrm{HR}$ & \multicolumn{2}{|c|}{$95 \%$ Cl } \\
\hline \multicolumn{12}{|l|}{$\overline{C O P D}$} \\
\hline \multirow[t]{3}{*}{ Age } & $<60$ & 28,854 & 1.07 & 1.04 & 1.11 & 1.05 & 1.02 & 1.08 & 1.14 & 1.11 & 1.17 \\
\hline & $60-74$ & 32,092 & 1.00 & 0.97 & 1.03 & 1.06 & 1.03 & 1.08 & 1.08 & 1.06 & 1.11 \\
\hline & $>=75$ & 13,597 & 1.01 & 0.98 & 1.04 & 1.08 & 1.05 & 1.11 & 1.02 & 0.99 & 1.05 \\
\hline \multirow[t]{2}{*}{ Sex } & Men & 39,111 & 1.04 & 1.01 & 1.06 & 1.07 & 1.05 & 1.10 & 1.10 & 1.07 & 1.14 \\
\hline & Women & 35,432 & 1.06 & 1.03 & 1.08 & 1.06 & 1.04 & 1.09 & 1.10 & 1.05 & 1.14 \\
\hline \multicolumn{12}{|l|}{ Asthma } \\
\hline \multirow[t]{2}{*}{ Age } & $<60$ & 58,934 & 1.01 & 1.00 & 1.02 & 1.01 & 0.99 & 1.03 & 1.04 & 1.02 & 1.06 \\
\hline & $60-74$ & 21,754 & 1.00 & 0.98 & 1.02 & 1.04 & 1.02 & 1.07 & 1.03 & 1.01 & 1.05 \\
\hline \multirow[t]{3}{*}{ Sex } & $>=75$ & 6453 & 1.01 & 0.97 & 1.05 & 1.02 & 0.98 & 1.06 & 1.00 & 0.97 & 1.04 \\
\hline & Men & 35,019 & 1.02 & 1.00 & 1.04 & 1.02 & 1.00 & 1.03 & 1.03 & 1.01 & 1.04 \\
\hline & Women & 52,122 & 1.00 & 0.98 & 1.01 & 1.03 & 1.01 & 1.04 & 1.03 & 1.01 & 1.05 \\
\hline \multicolumn{12}{|c|}{ Lung Cancer } \\
\hline \multirow[t]{2}{*}{ Age } & $<60$ & 5891 & 1.00 & 0.96 & 1.04 & 1.04 & 1.01 & 1.08 & 1.04 & 1.01 & 1.08 \\
\hline & $60-74$ & 5969 & 1.00 & 0.97 & 1.03 & 1.05 & 1.03 & 1.08 & 1.07 & 1.04 & 1.10 \\
\hline \multirow[t]{3}{*}{ Sex } & $>=75$ & 1048 & 1.01 & 0.93 & 1.09 & 1.04 & 0.98 & 1.10 & 1.02 & 0.93 & 1.10 \\
\hline & Men & 7085 & 1.00 & 0.96 & 1.04 & 1.06 & 1.02 & 1.09 & 1.09 & 1.05 & 1.12 \\
\hline & Women & 5823 & 0.98 & 0.93 & 1.03 & 1.06 & 1.03 & 1.10 & 1.06 & 1.02 & 1.10 \\
\hline
\end{tabular}


Table 7 Sensitivity analyses for the associations of respiratory disease incidence with $\mathrm{PM}_{2.5}$

\begin{tabular}{|c|c|c|c|c|c|c|c|c|c|}
\hline \multirow{3}{*}{$\begin{array}{l}\text { Sensitivity analysis } \\
\text { Results from the Main Analyses (Table 4) }\end{array}$} & \multicolumn{3}{|c|}{ COPD } & \multicolumn{3}{|c|}{ Asthma } & \multicolumn{3}{|c|}{ Lung cancer ${ }^{a}$} \\
\hline & \multirow{2}{*}{$\begin{array}{l}\mathrm{HR} \\
1.06\end{array}$} & \multicolumn{2}{|c|}{$95 \% \mathrm{Cl}$} & \multirow{2}{*}{$\begin{array}{l}\mathrm{HR} \\
1.02\end{array}$} & \multicolumn{2}{|c|}{$95 \% \mathrm{Cl}$} & \multirow{2}{*}{$\begin{array}{l}\mathrm{HR} \\
1.05\end{array}$} & \multicolumn{2}{|c|}{$95 \% \mathrm{Cl}$} \\
\hline & & 1.04 & 1.08 & & 1.00 & 1.04 & & 1.03 & 1.08 \\
\hline \multicolumn{10}{|l|}{ Two different time windows of exposure } \\
\hline 1 year before event & 1.05 & 1.04 & 1.07 & 1.01 & 1.00 & 1.03 & NA & NA & NA \\
\hline 2 year before event & 1.06 & 1.04 & 1.07 & 1.02 & 1.00 & 1.03 & NA & NA & NA \\
\hline \multicolumn{10}{|l|}{ Two different lags in the exposure } \\
\hline 0-year lag b & NA & NA & NA & NA & NA & NA & 1.04 & 1.01 & 1.08 \\
\hline 2-year lag ${ }^{c}$ & NA & NA & NA & NA & NA & NA & 1.05 & 1.02 & 1.08 \\
\hline $\begin{array}{l}\text { Restricted to subjects who lived at their baseline } \\
\text { addresses for } \geq 5 \text { years prior to cohort entry }\end{array}$ & 1.06 & 1.04 & 1.08 & 1.02 & 1.00 & 1.03 & 1.05 & 1.03 & 1.08 \\
\hline Adjusted for a linear term for time & 1.06 & 1.04 & 1.08 & 1.02 & 1.00 & 1.04 & 1.05 & 1.03 & 1.08 \\
\hline Adjusted for the distance to roadways & 1.06 & 1.04 & 1.08 & 1.02 & 1.00 & 1.03 & 1.05 & 1.03 & 1.08 \\
\hline \multicolumn{10}{|l|}{$\begin{array}{l}\text { Indirect adjustment } \\
\text { (with HRs directly calculated from the CCHS cohort) }\end{array}$} \\
\hline + Smoking only & 1.04 & 0.99 & 1.08 & 1.02 & 1.00 & 1.04 & 1.03 & 0.95 & 1.11 \\
\hline + Smoking and BMl & 1.04 & 0.97 & 1.09 & 1.03 & 1.00 & 1.05 & 1.01 & 0.93 & 1.10 \\
\hline
\end{tabular}

${ }^{a}$ The cohort was followed up from April 1, 2001 to December 31, 2012

${ }^{\mathrm{b}}$ The cohort was followed up from April 1, 1996 to December 31, 2012

'The cohort was followed up from April 1, 1998 to December 31, 2012. All models are stratified by age and sex, include a frailty term for neighborhoods, and are adjusted for neighborhood-level covariates

impact on effect estimates for pollutants with high spatial variability.

A previous review of epidemiological studies related to air pollution and adult-onset asthma found inconsistent evidence in support of a causal relationship and identified the need for large-scale cohort studies and the inclusion of local-scale traffic pollutants like UFPs [18]. Our investigation addressed both of these needs and our results indicate that $\mathrm{NO}_{2}$ and $\mathrm{PM}_{2.5}$ may each contribute to increases in the incidence of adult-onset asthma independent of other potential risk factors. The results of two other large cohort studies also support these

Table 8 Sensitivity analyses for the associations of respiratory disease incidence with $\mathrm{NO}_{2}$ in fully adjusted models

\begin{tabular}{|c|c|c|c|c|c|c|c|c|c|}
\hline \multirow{3}{*}{$\begin{array}{l}\text { Sensitivity analysis } \\
\text { Results from the Main Analyses (Table 4) }\end{array}$} & \multicolumn{3}{|c|}{ COPD } & \multicolumn{3}{|c|}{ Asthma } & \multicolumn{3}{|c|}{ Lung cancer $^{a}$} \\
\hline & \multirow{2}{*}{$\begin{array}{l}\mathrm{HR} \\
1.11\end{array}$} & \multicolumn{2}{|c|}{$95 \% \mathrm{Cl}$} & \multirow{2}{*}{$\frac{\mathrm{HR}}{1.03}$} & \multicolumn{2}{|c|}{$95 \% \mathrm{Cl}$} & \multirow{2}{*}{$\begin{array}{l}\mathrm{HR} \\
1.07\end{array}$} & \multicolumn{2}{|c|}{$95 \% \mathrm{Cl}$} \\
\hline & & 1.07 & 1.15 & & 1.02 & 1.05 & & 1.04 & 1.10 \\
\hline \multicolumn{10}{|l|}{ Two different time windows of exposure } \\
\hline 1 year before event & 1.11 & 1.07 & 1.15 & 1.05 & 1.04 & 1.06 & NA & NA & NA \\
\hline 2 year before event & 1.11 & 1.07 & 1.15 & 1.05 & 1.04 & 1.06 & NA & NA & NA \\
\hline \multicolumn{10}{|l|}{ Two different lags in the exposure } \\
\hline 0-year lag b & NA & NA & NA & NA & NA & NA & 1.10 & 1.08 & 1.13 \\
\hline 2-year lag c & NA & NA & NA & NA & NA & NA & 1.10 & 1.07 & 1.12 \\
\hline $\begin{array}{l}\text { Restricted to subjects who lived at their baseline } \\
\text { addresses for } \geq 5 \text { years prior to cohort entry }\end{array}$ & 1.11 & 1.07 & 1.15 & 1.05 & 1.04 & 1.06 & 1.07 & 1.04 & 1.10 \\
\hline Adjusted for a linear term for time & 1.11 & 1.07 & 1.15 & 1.03 & 1.02 & 1.05 & 1.07 & 1.04 & 1.10 \\
\hline Adjusted for the distance to roadways & 1.06 & 1.03 & 1.09 & 1.02 & 1.01 & 1.03 & 1.04 & 1.01 & 1.07 \\
\hline \multicolumn{10}{|l|}{$\begin{array}{l}\text { Indirect adjustment } \\
\text { (with HRs directly calculated from the CCHS cohort) }\end{array}$} \\
\hline + Smoking only & 1.08 & 1.03 & 1.13 & 1.03 & 1.02 & 1.04 & 1.02 & 0.97 & 1.08 \\
\hline + Smoking and BMI & 1.09 & 1.04 & 1.15 & 1.04 & 1.02 & 1.05 & 1.01 & 0.95 & 1.07 \\
\hline
\end{tabular}

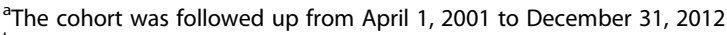

${ }^{\mathrm{b}}$ The cohort was followed up from April 1, 1996 to December 31, 2012

'The cohort was followed up from April 1, 1998 to December 31, 2012. All models are stratified by age and sex, include a frailty term for neighborhoods, and are adjusted for neighborhood-level covariates 
findings. Specifically, Young et al. [19] reported positive associations between incident adult-onset asthma/ wheeze and ambient $\mathrm{PM}_{2.5}$ and $\mathrm{NO}_{2}$ concentrations among approximately 50,000 women followed over a 4year period as part of the United States Sister Study cohort. Moreover, a combined analysis of six European cohorts including approximately 24,000 subjects reported positive associations between ambient $\mathrm{PM}_{2.5} / \mathrm{NO}_{2}$ and the development of adult onset asthma [20]. Collectively, evidence from these recent large prospective cohort studies suggests that ambient air pollutants including $\mathrm{NO}_{2}$ and $\mathrm{PM}_{2.5}$ may contribute to a modest increase in the incidence of adult-onset asthma.

Epidemiological evidence related long-term air pollution exposures and COPD incidence is somewhat limited and remains inconclusive [21]. In particular, two recent cohort studies found little evidence of important relationships between $\mathrm{PM}_{2.5}, \mathrm{NO}_{2}$, and COPD incidence. Specifically, Gan et al. [22] reported weak associations between $\mathrm{PM}_{2.5}, \mathrm{NO}_{2}$, and COPD hospitalizations/mortality in a cohort of approximately 500,000 subjects in Vancouver, Canada followed over a 4-year period. Similarly, a large national cohort study in England including more than 800,000 subjects found little evidence of an important association between $\mathrm{PM}_{2.5}, \mathrm{NO}_{2}$ and COPD incidence [23]. Conversely, Andersen et al. [24] reported a positive association between long-term exposure to $\mathrm{NO}_{2}$ and incident COPD in a Danish cohort study of approximately 57,000 subjects followed between 1993 and 2006. While our findings support modest association between $\mathrm{PM}_{2.5}, \mathrm{NO}_{2}$ and COPD incidence (and possibly UFPs), collective evidence remains limited.

This study had a number of important advantages including large numbers of incident cases and detailed exposure information for multiple air pollutants accounting for subject mobility; however, it is important to note several limitations. First, it is difficult to compare the magnitude of associations across pollutants as different exposure models were used for each air pollutant. Therefore, differences in exposure measurement error might have resulted in more/ less bias in associations for a given air pollutant depending on the degree to which residential exposure estimates (assigned to postal code centroids) reflected true long-term personal exposures. This measurement error likely contains components of both Classical (i.e. estimated ambient concentrations distribute around true ambient concentrations) and Berkson type measurement error (true personal exposures distributed around estimated mean ambient concentrations). As this error is likely non-differential with respect to survival time, the Classical measurement error component would tend to bias risk estimates toward the null in proportion to the correlation between measured exposures and true long-term personal exposures (which is unknown and is not provided by the model evaluation $R^{2}$ values). The
Berkson component of measurement error would not bias risk estimates but would decrease the precision of risk estimates. Therefore, the hazard ratios presented in this study likely underestimate the true magnitudes of associations between long-term exposure to air pollution and respiratory disease incidence.

For UFPs, the exposure model was based on spatial monitoring data collected after the follow-up period and this may have contributed to the null associations observed in our analyses. While analysis of long-term trends would help to clarify this question, the data required to support such an analysis do not exist. Moreover, UFPs are only weakly correlated with ambient $\mathrm{NO}_{2}$ and $\mathrm{PM}_{2.5}$ and thus trends in these pollutants cannot be used to infer trends in UFPs. What seems likely is that our model may underestimate true long-term exposure levels owing to decreases in vehicle emissions over time. However, spatial differences in UFP concentrations are likely more stable over time because spatial differences are primarily impacted by changes in the spatial patterns of diesel traffic (primarily large diesel vehicles). Since large diesel vehicles remain concentrated on major roadways, contrasts between high-traffic and low-traffic areas are likely preserved over time. Therefore, our model likely provides useful estimates of the relationship between health outcomes and changes in UFP exposure but may not be appropriate for determining absolute concentrations at which health effects occur (i.e. some minimum exposure threshold).

Another limitation is that we did not have individual level data on smoking behavior which is an important risk factor for all of the outcomes examined. To address this limitation, we used an indirect method of confounder adjustment based on pollutant-outcome associations in a second cohort available in the Toronto area and observed important changes in our effect estimates when this method was applied. However, we cannot rule out residual confounding by smoking.

\section{Conclusions}

We did not observe clear evidence of positive associations between long-term exposure to ambient UFPs and the incidence of lung cancer, COPD, or adult onset asthma. Our findings do suggest a possible association between UFPs and COPD but this association was sensitive to other air pollutants. In general, our findings require further replication in future cohort analyses as few studies have examined the chronic health effects of ambient UFPs to date.

\section{Additional files}

Additional file 1: Table S1. Linear associations between smoking and $\mathrm{BMI}$ and concentrations of UFPs, PM2.5, and $\mathrm{NO}_{2}$. Table S2. Hazard ratios (HR) and $95 \% \mathrm{Cls}$ for the incidence of chronic obstructive pulmonary 
disease (COPD), adult-onset asthma and lung cancer in relation to an IQR increases in UFPs and $\mathrm{PM}_{2.5}$ across tertiles of $\mathrm{NO}_{2}$. Table S3. Sensitivity analyses for the associations of respiratory disease incidence with UFPS. Figure S1. A scatter plot of ultrafine particles (count $/ \mathrm{cm}^{3}$ ) and $\mathrm{NO}_{2}(\mathrm{ppb})$ concentrations at baseline. (DOCX $77 \mathrm{~kb}$ )

\section{Abbreviations}

AMI: Acute myocardial infarction; BMI: Body mass index; CCHS: Canadian community health survey; CHF: Congestive heart failure; COPD: Chronic obstructive pulmonary disease; HR: Hazard ratio; ICD: International classification of diseases; ICES: Institute for clinical and evaluative sciences; ONPHEC: Ontario population health and environment cohort; UFPs: Ultrafine particles

\section{Acknowledgements}

The authors would like to thank Dr. Eric Lavigne for his comments in reviewing the paper.

\section{Funding}

This study was funded by Health Canada and supported by Public Health Ontario (PHO) and the Institute for Clinical Evaluative Sciences (ICES), which is funded by an annual grant from the Ontario Ministry of Health and Long-Term Care (MOHLTC). Parts of this material are based on data and information compiled and provided by the Canadian Information Health Institute (CIHI). Dr. Weichenthal also received financial support from a GRePEC salary award funded by the Cancer Research Society, the Quebec Ministry of Economy, Science and Innovation, and FRSQ (Fonds de recherche du Québec-Santé).

\section{Availability of data and materials}

The exposure models/data used in this study are available upon request to support future investigations and are described in the references $[4,6,9]$. The cohort data are housed at the Institute for Clinical Evaluative Sciences and cannot be distributed and must be analyzed on site.

\section{Author's contributions}

SW was the lead author and developed the UFP exposure model with $\mathrm{MH}$ and KVR. LB and $\mathrm{HC}$ conducted all statistical analyses with input from RB. MJ developed the $\mathrm{NO}_{2}$ exposure model and $\mathrm{RM}$ and $\mathrm{AD}$ provided the $\mathrm{PM}_{25}$ exposure data. All author read and approved the final manuscript, provided comments, and contributed to preparing the final document.

\section{Competing interests}

The authors declare that they have no competing interests.

\section{Consent for publication}

Not applicable.

\section{Ethics approval and consent to participate}

The Research Ethics Board of Sunnybrook Health Sciences Centre, Toronto approved the study.

\section{Disclaimer}

Not applicable.

\footnotetext{
Author details

'Department of Epidemiology, Biostatistics, and Occupational Health and Gerald Bronfman Department of Oncology, McGill University, 1020 Pine Avenue, West, Montreal, QC H3A 1A2, Canada. ${ }^{2}$ Air Health Science Division, Health Canada, Ottawa, Canada. ${ }^{3}$ Public Health Ontario, Toronto, Canada. ${ }^{4}$ Institute for Clinical Evaluative Sciences, Toronto, ON, Canada. ${ }^{5}$ Department of Civil Engineering, University of Toronto, Toronto, Canada. ${ }^{6}$ Department of Family and Community Medicine, University of Toronto, Toronto, ON, Canada. ' School of Public Health, University of California, Los Angeles, CA, USA. ${ }^{8}$ Dalhousie University, Halifax, Nova Scotia, Canada.

${ }^{9}$ Harvard-Smithsonian Center for Astrophysics, Cambridge, MA, USA.

${ }^{10}$ Population Studies Division, Health Canada, Ottawa, Canada. ${ }^{11}$ Dalla Lana

School of Public Health, University of Toronto, Toronto, ON, Canada.
}

Received: 12 January 2017 Accepted: 11 June 2017

Published online: 19 June 2017

\section{References}

1. Weichenthal S. Selected physiological effects of ultrafine particles in acute cardiovascular morbidity. Environ Res. 2012;115:26-36.

2. Evans KA, Halterman JS, Hopke PK, Fagnano M, Rich DQ. Increased ultrafine particles and carbon monoxide concentrations are associated with asthma exacerbation among urban children. Environ Res. 2014:129:11-9.

3. Ostro B, Hu J, Goldberg D, Reynolds P, Hertz A, Bernstein L, et al. Associations of mortality with long-term exposures to fine and ultrafine particles, species and sources: Results from the California teachers study cohort. Environ Health Perspect. 2015:123(6):549-56.

4. Weichenthal S, Van Ryswyk K, Goldstein A, Shekarrizfard M, Hatzopoulou M. Characterizing the spatial distribution of ambient ultrafine particles in Toronto, Canada: A land use regression model. Environ Pollut. 2016;208(Pt A):241-8.

5. Chen H, Kwong JC, Copes R, Villeneuve PJ, Goldberg MS, Weichenthal S, van Donkelaar A, Jerrett M, Martin RV, Brook JR, Kopp A, Burnett RT. Cohort profile: The Ontario Population Health and Environment Cohort (ONPHEC). Int J Epidemiol 2016; Epub ahead of print Apr. 20. doi:10.1093/ije/dyw030

6. Jerrett M, Arain MA, Kanaroglou P, Beckerman B, Crouse D, Gilbert NL, et al. Modeling the intraurban variability of ambient pollution in Toronto, Canada. J Toxicol Environ Health A. 2007;70(3-4):200-12.

7. Weichenthal S, Van Rysuyk K, Kulka R, Sun L, Wallace L, Joseph L. In-vehicle exposures to particulate air pollution in Canadian metropolitan areas: The urban transportation exposure study. Environ Sci Technol. 2015:49(1):597-605.

8. Montagne DR, Hoek G, Klompmaker JO, Wang M, Meliefste K, Brunekreef B. Land use regression models for ultrafine particles and black carbon based on short-term monitoring predict past spatial variation. Environ Sci Technol. 2015;49(14):8712-20.

9. van Donkelaar A, Martin RV, Spurr RJ, Burnett RT. High-resolution satellitederived PM2.5 from optimal estimation and geographically weighted regression over North America. Environ Sci Technol. 2015;49(17):10482-91.

10. Shin HH, Cakmak S, Brion O, Villeneuve P, Turner MC, Goldberg MS, et al. Indirect adjustment for multiple missing variables applicable to environmental epidemiology. Environ Res. 2014;134:482-7.

11. Wang A, Kubo J, Luo J, Desai M, Hedlin H, Henderson M, et al. Active and passive smoking in relation to lung cancer incidence in the Women's health initiative observational study prospective cohort. Ann Oncol. 2015;26:221-30.

12. Crouse DL, Peters PA, Hystad P, Brook JR, van Donkelaar A, Martin RV, et al. Ambient PM2.5, O3, and NO2 exposures and associations with mortality over 16 years of follow-up in the Canadian census health and environment cohort (CanCHEC). Environ Health Perspect. 2015:123(11):1180-6.

13. Weichenthal S, Hatzopoulou M, Goldberg M. Exposure to traffic-related air pollution during physical activity and acute changes in blood pressure, autonomic and micro-vascular function in women: A cross-over study. Part Fibre Toxicol. 2014:11:70

14. Hamra GB, Guha N, Cohen AJ, Laden F, Raaschou-Nielsen O, Samet JM, et al. Outdoor particulate matter exposure and lung cancer: A systematic review and meta-analysis. Environ Health Perspect. 2014;122(9):906-11.

15. Hamra GB, Laden F, Cohen AJ, Raaschou-Nielsen O, Brauer M, Loomis D. Lung cancer and exposure to nitrogen dioxide and traffic: A systematic review and meta-analysis. Environ Health Persepct. 2015;123(11):1107-12.

16. Benbrahim-Tallaa L, Baan RA, Grosee Y, Lauby-Secretan B, El Ghissassi F, Bouvard V, et al. Carcinogenicity of diesel-engine and gasoline-engine exhausts and some nitroarenes. Lancet Oncology 2012. 2012:13(7):663-4.

17. Wang Y, Zhu Y, Salinas R, Ramirez D, Karnae S, John K. Roadside measurements of ultrafine particles at a busy urban intersection. J Air Waste Manage Assoc. 2008;58(11):1449-57.

18. Jacquemin B, Schikowski T, Carsin AE, Hansell A, Kramer U, Sunyer J, et al. The role of air pollution in adult-onset asthma: A review of the current evidence. Semin Respir Crit Care Med. 2012;33(6):606-19.

19. Young MT, Sandler DP, DeRoo LA, Vedal S, Kaufmann JD, London SJ. Ambient air pollution exposure and incident adult asthma in a nationwide cohort of U.S. women. Am J Respir Crit Care Med. 2014:190(8):914-21.

20. Jacuemin B, Siroux V, Sanchez M, Carsin AE, Schikowski T, et al. Ambient air pollution and adult asthma incidence in six European cohorts (ESCAPE). Environ Health Perspect. 2015;123(6):613-21.

21. Schikowski T, Mills IC, Anderson HR, Cohen A, Hansell A, Kauffmann F, et al. Ambient air pollution: A cause of COPD? Eur Respir J. 2014;43(1):250-63. 
22. Gan WQ, FitzGerald JM, Carlsten C, Sadatsafavi M, Brauer M. Associations of ambient air pollution with chronic obstructive pulmonary disease hospitalization and mortality. Am J Respir Crit Care Med. 2013;187(7):721-7.

23. Atkinson RW, Carey IM, Kent AJ, van Staa TP, Anderson HR, Cook DG. Longterm exposure to outdoor air pollution and the incidence of chronic obstructive pulmonary disease in a national English cohort. Occup Environ Med. 2015;72(1):42-8.

24. Andersen ZJ, Hvidberg M, Jensen SS, Ketzel M, Loft S, Sorensen M, et al. Chronic obstructive pulmonary disease and long-term exposure to trafficrelated air pollution. Am J Respir Crit Care Med. 2011;183(4):455-61.

Submit your next manuscript to BioMed Central and we will help you at every step:

- We accept pre-submission inquiries

- Our selector tool helps you to find the most relevant journal

- We provide round the clock customer support

- Convenient online submission

- Thorough peer review

- Inclusion in PubMed and all major indexing services

- Maximum visibility for your research

Submit your manuscript at www.biomedcentral.com/submit
Biomed Central 